DOI: 10.14526/2070-4798-2020-15-1-96-105

\title{
Orientation, content and methodology of comprehensive fitness training for men of the first period of adulthood
}

\author{
Olga N. Stepanova ${ }^{1 *}$, Sergey V. Savin ${ }^{2}$ \\ ${ }^{1}$ Moscow State Pedagogical University, Moscow, Russia \\ ORCID: oOoo-Ooo2-4114-2801, stepanova.olga.mpgu@gmail.com* \\ ${ }^{2}$ Russian State Social University, Moscow, Russia \\ ORCID: oooo-Ooo2-3334-1114,fizzdorovie@gmail.com
}

\begin{abstract}
As the results of numerous scientific studies show, the first serious health problems in men begin already in the first period of adulthood - from 22 to 35 years. At the same time, it is at this age that a person maintains a high level of fitness for motor functions, favorable conditions are formed for achieving significant health and even sports results. In recent years, a lot of material has been accumulated on the problems of substantiating the effectiveness of fitness programs of homogeneous content: strength, aerobic, game, gymnastic, based on the use of swimming equipment, hatha yoga, etc. However, at the present stage, an integrated approach to the support of scientists and practitioners designing health-conditioning training programs. Materials. The article presents the results of testing and examinations of 35 men aged 22-35 years old. They are the clients of the Fitness Territory Fitness club (Moscow, Russia). Testing materials served as guidelines for substantiating orientation and content, as well as developing methods for comprehensive fitness training for men of the first adulthood period. Research methods. Analysis and generalization of literary primary sources on the research problem, survey (questionnaire, interviews), medical history, anthropometric measurements, $\mathrm{PWC}_{170}$ sample, maximum oxygen consumption measurement, general performance coefficient, body mass index, Romberg test, control exercises method, pedagogical experiment, statistical data processing methods. Results. A technique has been developed for comprehensive fitness training for men of the first adulthood period, which includes four thematic blocks of physical exercises: aerobic, functional, corrective and preventive, and relaxation. Conclusion. The use of the comprehensive fitness training methodology contributed to the effective solution of the health improvement tasks, normalizing the functional state of the cardiorespiratory system, improving the psychoemotional and general somatic state, reducing the severity of pain in the cervical-collar, thoracic and lumbosacral spine, increasing the level of physical fitness and general physical performance, improving the physique of men of the first period of adulthood.

Keywords: men of adulthood, fitness testing, comprehensive fitness training.
\end{abstract}

For citation: Olga N. Stepanova*, Sergey V. Savin. Orientation, content and methodology of comprehensive fitness training for men of the first period of adulthood. Russian Journal of Physical Education and Sport. 2020; 15(1): 80-86. DOI: 10.14526/2070-4798-2020-15-1-96-105

\section{INTRODUCTION}

An important role in national health improvement nowadays belongs to healthimproving physical culture and fitness [2]. The results of many scientific research works show that most diseases of a person begin when the organism is on the edge of norm and pathology [5, 7]. 70\% of adults of this country are in this negative for health state condition and the first serious problems with health among men start during the $1^{\text {st }}$ period of adulthood - since 22 till 35 years old [3]. At the same time, during this age period a person preserves a high level of motor functions training capacity, and favorable preconditions for considerable health- improving and sports results achievement $[1,4]$.

In recent years the questions of healthimproving fitness-training content substantiation and organization among people of adulthood were studied by I.V. Adamova [1], N.N. Vengerova [2], S.A. Golovanov [2], L.D. NazarenkoandV.M. Vavilov [6], N.I. Perevoznikova [8], S.V. Savin, O.N. Stepanova [9], A.V. Stafeevaand A.L. Deryabina [11] and others. At the same time, most mentioned above works and other research works were tested either among women or among men of the $2^{\text {nd }}$ period of adulthood.

Speaking about other research works, held among men of the $1^{\text {st }}$ adulthood, most works 
substantiate the effectiveness of homogeneous content fitness-programs (power [11,12], aerobic $[3,9,13]$, playing $[8,10,14]$, gymnastic $[6,15,16]$, based on swimming means use [1], hatha yoga [1] and etc.). At the same time, at a modern stage of fitness theory and methodology development great attention is paid to a complex approach to healthimproving conditional program of (fitness) training.

In this connection the aim of the research is the orientation and content substantiation and the methodology creation of complex fitness-training in men of the $1^{\text {st }}$ adulthood (22-35 years old).

\section{RESEARCH METHODS}

In order to achieve the set aim we used the following research methods: information sources analysis and summarizing, questioning (questionnaire survey, conversations), anamnesis, anthropometric measures, $\mathrm{PWC}_{170}$ test, maximum oxygen consumption estimation, general working capacity coefficient, body weight index, Romberg test, method of control exercises, pedagogical experiment, methods of statistical data handling.

The research was held on the basis of fitnessclub "Territory of Fitness" (Moscow). The research sampling included 35 men of the $1^{\text {st }}$ adulthood (2235 years old). They were going to the mentioned above fitness-club.

\section{RESULTS AND DISCUSSION}

As the results of questioning showed the dominant aims (motives) of going in for fitness for these 35 men (fitness-club "Territory of Fitness") were the following: desire to improve health state - the risk of health disorders decrease (23\% of respondents), lifetime increase (11\%), rehabilitation after the experienced diseases (6\%) and injuries (3\%); desire to improve appearance - constitution improvement (17\%), weight correction (fat decrease or muscles mass increase) (14\%), desire to look great for oneself and other people around (11\%); need for rest - accumulated emotional tension decrease (9\%), and communication (6\%). Nobody mentioned the motive of having more motor activity or getting physical load.

During the research we stated the kinds and frequency of locomotor apparatus disorders occurrence among 35 men of the $1^{\text {st }}$ adulthood - the clients of "Territory of Fitness" fitness club. Among the most commonly occurring disorders are the following: overtone of back and neck, chest and loins muscles (69\%) and scoliosis in chest, interior thoracic segment and lumbosacral spine (61\%). Then comes lordosis, hyper lordosis in cervical parts and lumbar spine, kyphosis in cervical parts (48\%) and shoulder girdle asymmetry among $42 \%$ of the respondents. $11 \%$ of the respondents have cervical, thoracic section and lumbar spine osteochondrosis, $8 \%$ of respondents have weak pectoral muscle sling and flat-footedness. Such diseases as intervertebral hernia, arthrosis, not stable cervical parts have $4 \%$ of the respondents (each of the diseases). As the conversations showed, the revealed situation of disorders is conditioned by a low level of motor activity: most respondents have professional and habitual hypokinesia.

The results of the held anthropometric measurements show that all constitution indices and physical development indices among the men of the $1^{\text {st }}$ adulthood, who train at "Territory of Fitness" fitness club (height 170-185 cm) have the following body sizes: circumferences of chest $(99,7 \pm 10,4 \mathrm{~cm})$, waist $(88,6 \pm 13,8 \mathrm{~cm})$, hips $(99,7 \pm 4,7 \mathrm{~cm})$ correspond or are close to their age-related norms. The exception is body weight index ( $25,5 \pm 4,7$ units). It shows the problem of overweight among $42 \%$ of the respondents and the weight deficiency among $6 \%$ of the respondents.

The results of the functional fitness-test showed the following:

- deviation from the norm (decrease) in the following indices: systolic pressure-65,4\%, diastolic pressure $-61,5 \%$, HR at rest $-84,6 \%, \mathrm{MOC}-23 \%$, general working capacity $-53,8 \%$, Romberg test 26,9\%of the respondents;

- in the average HR indices at rest in men correspond with "good" state (55-65 beats/min) of heart muscle, systolic (121-126 mm Hg) and diastolic (76-81 mm Hg) pressure indices correspond with "the average" health level;

- PWC $_{170}$ test results (950-1500 $\mathrm{kgm} / \mathrm{min}$ ) and MOC indices $(39-53 \mathrm{ml} / \mathrm{min} / \mathrm{kg})$ are at a necessary level. It proves "good" fitness and "good" adaptive level of respondents' organism to physical 
loads;

- General working capacity of the respondents was estimated as 17-22 units; in the average this result can be understood as "high";

- Romberg test ("stork" position) showed "good" level of the ability to hold static balance (1025 seconds).

Taking into account the results of the research, we created the methodology of complex fitness-training for men of the $1^{\text {st }}$ adulthood.

The main aims and objectives of this fitnesstraining are the following:

- First of all, personally important results of fitness lessons achievement: appearance improvement, constitution improvement, weight correction (weight decrease or increase); rehabilitation after the experienced diseases and injuries; psycho-emotional state improvement, rest after a hard working day;

- Secondly, the existing locomotor apparatus problems correction: spine muscle overtone decrease; bearing problems correction; spine and joints diseases prevention;

- Thirdly, constitution and weight indices normalization: fat weight decrease (in terms of muscle mass preservation or increase), weight normalization; circumference body sizes decrease. They go beyond age-related norms (waist, buttocks); body circumferences increase in a given localization (shoulders, hips and others);

- Fourthly, functional state of cardiorespiratory system normalization;

- Fifthly, the level of general physical working capacity increase: the level of general physical working capacity of age-related norms; the level of "not developed" physical qualities improvementgeneral (aerobic) enduranceandcoordinating abilities till the level of age-related norm.

During the research we used four thematic blocks (group of means) of physical exercises: aerobic, functional, correctional-preventive, relaxing (Mind\&Body) (table 1).

Table 1 -Thematic blocks of complex fitness-training in men of the $1^{\text {st }}$ adulthood, their orientation (objectives) and main means

\begin{tabular}{|c|c|c|}
\hline Thematic blocks & Orientation (objectives) & Means \\
\hline Aerobic & $\begin{array}{l}\text { The level of general (aerobic) } \\
\text { endurance, general working capacity } \\
\text { and functional state of cardiorespiratory } \\
\text { system (till age-related norm increase) } \\
\text { increase, fat mass decrease, weight } \\
\text { normalization, circumference body sizes } \\
\text { decrease (till age-related norms) }\end{array}$ & $\begin{array}{l}\text { Cyclic exercises at cardio training- } \\
\text { simulators: running track, step } \\
\text { machine, elliptic training simulator, } \\
\text { rowing training simulator and } \\
\text { bicycle simulator }\end{array}$ \\
\hline Functional & $\begin{array}{l}\text { The main muscle groups strengthening, } \\
\text { body constitution improvement and } \\
\text { appearance improvement, the level of } \\
\text { coordinating abilities increase }\end{array}$ & $\begin{array}{l}\text { Power oriented exercises(for muscle } \\
\text { mass increase and constitution } \\
\text { correction), exercises for power } \\
\text { endurance and coordination in a } \\
\text { form of circular training from a } \\
\text { functional training arsenal: at "not } \\
\text { stable surfaces"(fitball, hemisphere } \\
\text { "bosu"), with TRX loops, rubber } \\
\text { bandage, with own weight }\end{array}$ \\
\hline $\begin{array}{l}\text { Correction a }- \\
\text { preventive }\end{array}$ & $\begin{array}{l}\text { "Muscle corset" (abs muscles, spine } \\
\text { stabilizers) strengthening in order to } \\
\text { correct bearing, prevent spine and } \\
\text { joints diseases, for rehabilitation after } \\
\text { the diseases and injuries }\end{array}$ & $\begin{array}{l}\text { Exercises at block type training } \\
\text { simulators, with own weight, with } \\
\text { additional equipment, complexes } \\
\text { of exercises of remedial gymnastics } \\
\text { (depending on the existing problems } \\
\text { with health) }\end{array}$ \\
\hline 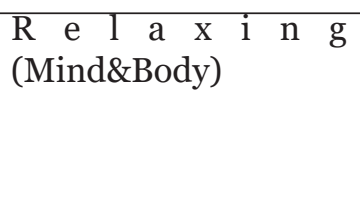 & $\begin{array}{l}\text { Psycho-emotional state normalization, } \\
\text { activity improvement in muscles } \\
\text { and joints, spine muscles hypertonia } \\
\text { decrease, the accumulated tension } \\
\text { decrease after a working day }\end{array}$ & $\begin{array}{l}\text { The exercises from the arsenal of } \\
\text { pilates, stretching, fitness-yoga, } \\
\text { respiratory gymnastics }\end{array}$ \\
\hline
\end{tabular}


The experimental methodology provides the methods of strictly regulated exercises use, repeated off-peak efforts, dynamic efforts, even-continuous, even-alternating, interval methods and the method of circular training.

Each health-improving training includes three parts: preparatory (warming-up), the main (aerobic, functional and correctional-preventive blocks) and the final part (relaxing block).

In different parts of the lesson pulse regimen would be not equal. During the preparatory part the recommended pulse regimen while using aerobic block exercises and general warming-up is 60-70\% form maximal $\mathrm{HR}_{\max }$ (115-130 beats/min). During the main part of the lesson: pulse regimen of the functional block is $65-75 \%$ fromHR $_{\text {max }}$ (within 120-140 beats/min), correctional-preventive block $-60-70 \%$ fromHR $_{\max }$ (115-130 beats/min). During the final part (relaxing block) it is recommended to have pulse regimen within $55^{-} 65 \%$ fromHR $_{\max }\left(105^{-}\right.$ 120 beats/min).

During intensive aerobic exercises pulse can be till $70-80 \%$ formmaximum value, $130-150$ beats/ min.

The offered methodology predicts not equal amount of lessons a week. At the initial stage it is recommended to have three lessons a week (6070 minutes each), during the main and the final stages (stabilizing) -4 times a week (duration 6070 minutes). At the main and the final stages for an intensive aerobic load we gave a separate day. Rest between the training lessons was one day.

The plan for the first 6 weeks of fitness is presented in a form of macro cycle, which includes 3 meso cycles (initial, mainand stabilizing) and 24 weeklymicro cycles(Table 2).

At the end of the 6th month pedagogical experiment, dedicated to the effectiveness of the offered methodology estimation, weight of the respondents decreased in the average for $3,8 \mathrm{~kg}$ $(4,3 \% ; \mathrm{P}<0,05)$ and became the norm. The index of body weight also became the norm, decreased in the average from 25,5till 24,7 $(\mathrm{P}<0,05)$ units.

The indices of constitution also improved among the respondents, which was reflected in waist (for $4,2 \mathrm{~cm}$ )and pelviscircumference decrease (for $2,7 \mathrm{~cm}(\mathrm{P}<0,05)$ ).

Positive, though statistically insignificant shifts were in HR indices at rest, systolic and diastolic blood pressure. It corresponded with "slightly above the norm" level. Romberg test results, PWC170test, MOC level and general working capacity coefficient had "perfect" values.

The respondents also underlined own psycho-emotional and general somatic state improvement, pain syndrome decrease in cervicalcollar, chest and lumbar- sacral zones, satisfaction with the results of the training lessons.

\section{CONCLUSION}

The methodology of complex fitnesstraining, which includes four thematic blocks of physical exercises - aerobic, functional, correctionpreventive and relaxing, provided effective health improvement, cardiorespiratory system functional state indices normalization, psycho-emotional state and general somatic state improvement, pain syndrome decrease in cervical- collar, chest and lumbar- sacral zones, the level of physical readiness and general physical working capacity increase, constitution parameters improvement in men of the 1st adulthood.

The results of the experimental work show the opportunity to use the offered methodology of complex fitness-training with men of the 1st adulthood and form the base for further research works connected with effective methodologies creation for health-improving-conditional training among the representatives of other socialdemographic and nosological groups of population. 


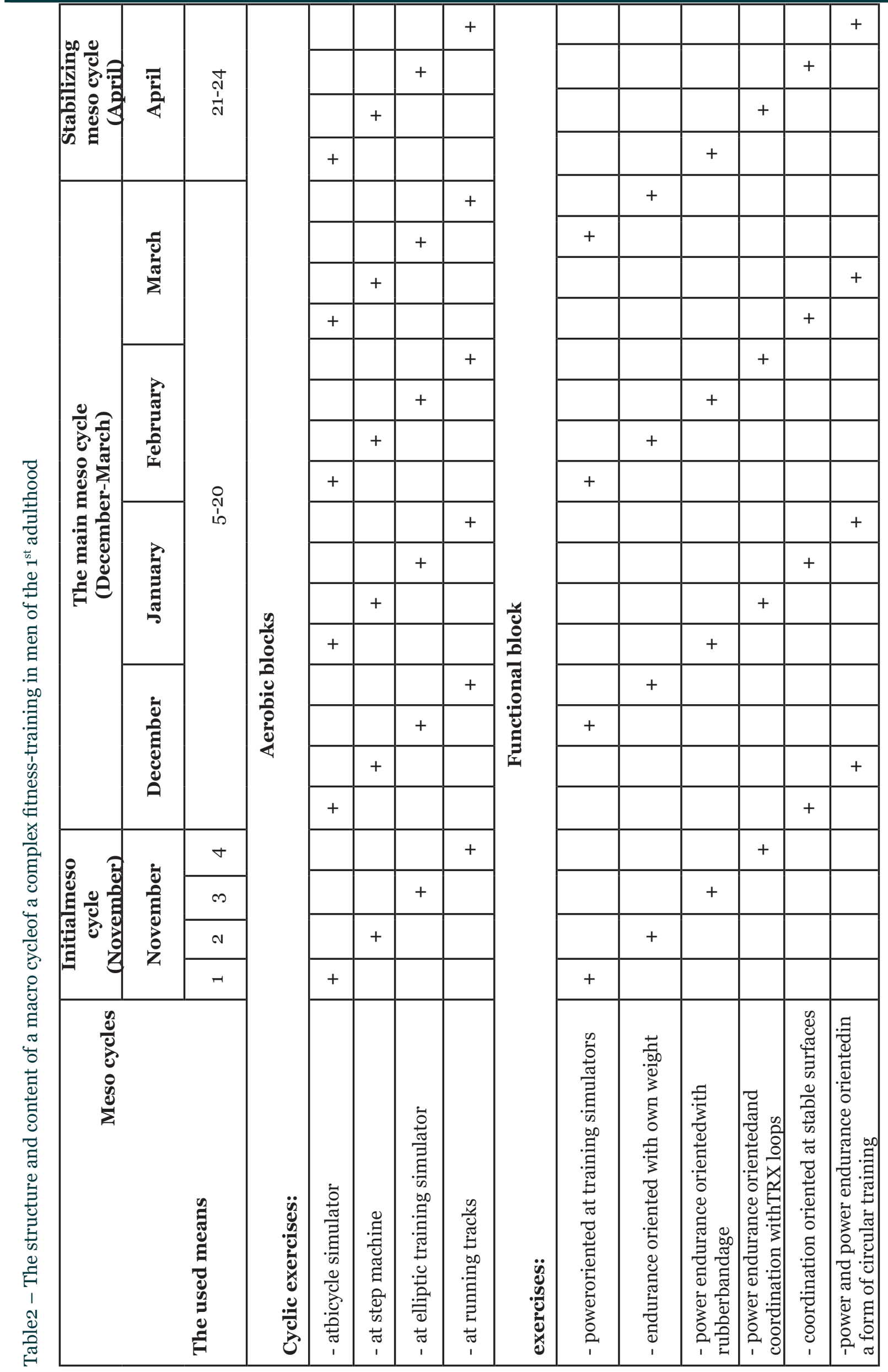




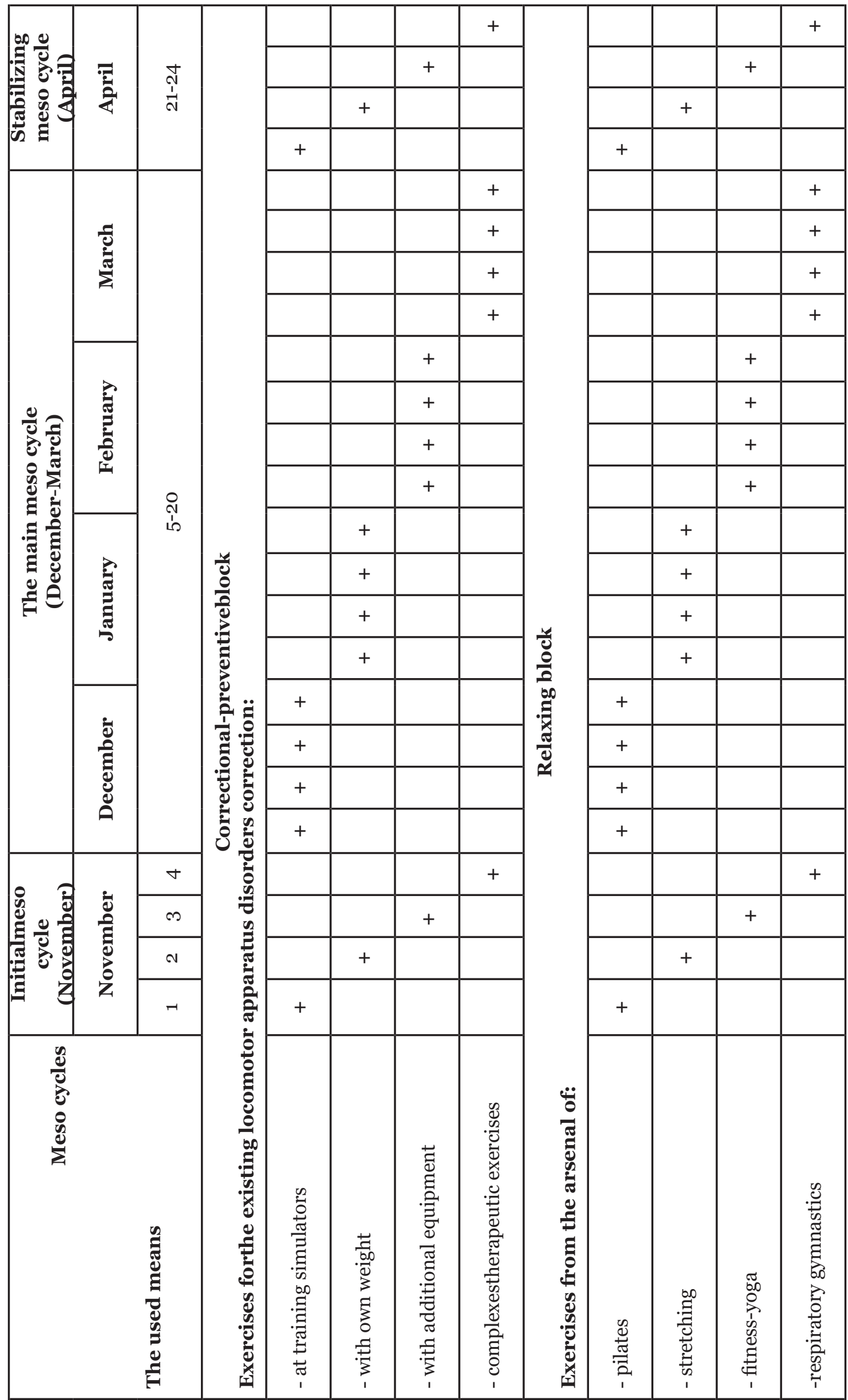




\section{REFERENCES}

1. Adamova I.V. Effectiveness of complex lessons with swimming and hatha-yoga influence onpsycho-physical state of 21-35 year-old men. Pedagogiko-psihologicheskie I medicobiologicheskie problemy fizicheskoj kul'tury I sporta $=$ Russian journal of Physical Education and Sport. 2019; 14(2): 43-47. DOI: 10.14526/20704798-2019-14-2-43-47 [In Russ., In Engl.]

2. Vengerova N.N., Kudashova L.T., Lyuk L.V. Fizkul'turno-ozdorovitel'nye tehnologï kondicionnoj napravlennosti [Physical culturehealth-improving technologies of conditional orientation]. Saint-Petersburg: Saint-Petersburg State Economical University. 2015: 91 [In Russ.].

3. Golovanova S.A. Complex program of health correctionamong men with obesity in terms of aerobic physical loads. Teoriay I praktika fizicheskoj kul'tury = Theory and practice of physical culture. 2014; 3: 57-61 [In Russ., In Engl.].

4. Levushkin S.P., Sonkin V.D. Age-related changes in physical readiness of the Russian Federation population according to the results of RLD (GTO) complex normative fulfillment. Teoriay I praktika fizicheskoj kul'tury = Theory and practice of physical culture. 2019; 1: 89 [In Russ., In Engl.]. 5. Lutchenko I.G., Perevoznikova I.I., Vysotskiy Yu.M. Scientific-theoretical aspects of a person's ontokinesiological potential development. Teoriay I praktika fizicheskoj kul'tury = Theory and practice of physical culture. 2015; 3: 61 [In Russ., In Engl.].

6. Nazarenko L.D., Vavilov V.M. Physiological mechanism of body-building means influence on men of the second adulthood (40-49 yearsold). Pedagogiko-psihologicheskie I medicobiologicheskie problemy fizicheskoj kul'tury I sporta = Pedagogico-psychological and medicobiological problems of physical culture and sport. 2014; 9 (2): 134-140. DOI: 10.14526/00_1111_18 [In Russ., In Engl.].

7. Pasmurova L.E. Modern problems of a person's health state. Pedagogiko-psihologicheskie I medico-biologicheskie problemy fizicheskoj kul'tury I sporta = Pedagogico-psychological and medico-biological problems of physical culture and sport. 2008; 3 (3).104-110. URL: http:// journalsport.ru/images/vipuski/3-1/3.pdf [In Russ., In Engl.]
8. Perevoznikova N.I. Game fitnesstechnology in the system motor activityamong men ofadulthood. Candidate's thesis. Saint-Petersburg 2017: 183 .

9. Savin S.V., Stepanova O.N. Methodology of functional (fitness-) training among women ofadulthood. Kul'tura fizicheskaya I zdorov'e. 2017, 1 (61): 42-45 [In Russ.].

10. Savin S.V., Stepanova O.N., Sokolova V.S., Nikolaev I.V. Ozdorovitel'naya trenirovka lic zrelogo vozrasta: napravlennost', soderzhanie, metodiki [Health improving training among people of adulthood: orientation, content, methodology]. Moscow: Moscow Pedagogical State University. 2017: 200 [In Russ.]

11. Stafeev A.V., Deryabina A.L. The effectiveness of physical culture-health improving lessons of power oriented fitness among men of adulthood. Uspehi sovremennoj nauki I obrazovaniya. 2016; 1(12): 209-212 [In Russ.].

12. Bogaerts A., Delecluse C., Claessens A.L., Coudyzer W.,Boonen S., Verschuerenm S.M. Impact of whole-body vibration training versus fitness training on muscle strength and muscle mass in older men: A 1-year randomized controlled trial. Journal of Gerontology A: Biological Sciences. 2007; 62: 630-635. DOI: 10.1093/Gerona/62.6.630.

13. Brooke-Wavell K., Mansfield N.J. Risks and benefits of whole body vibration training in older people. Age and Ageing. 2009; 38: 254-255. DOI: 10.1093/ageing/afpo36.

14. Cardinale M., Soiza R.L., Lieper J.B., Gibson A., Primrose W.R. Hormonal responses to a single session of whole body vibration exercise in elderly individuals. British Journal of Sports Medicine. 2010; 44: 284-288. DOI: 10.1136/ bjsm.2007.043232.

15. Ferri A., Scaglioni G., Pousson M., Capodaglio P., Van Hoecke J., Narici M.V. Strength and power changes of the human plantar flexors and knee extensors in response to resistance training in old age. Acta Physiologica Scandinavica. 2003; 177: 69/78. DOI: 10.1046/j.1365-201X.2003.01050.x.

16. Lau R.W., Liao L.R., Yu F., Teo T., Chung R.C., Pang M.Y. The effects of whole body vibration therapy on bone mineral density and leg muscle strength in older adults: A systematic review and meta-analysis. Clinical Rehabilitation. 2011; 25: 975-988. DOI: 10.1177/0269215511405078.

Submitted: 20.01.2020

Author's information:

Olga N. Stepanova - Doctor of Pedagogics, Professor, MoscowPedagogical State University, 119571, Russia, Moscow, Vernadskogo ave., House 88, e-mail: stepanova.olga.mpgu@gmail.com

Sergey V. Savin - Candidate of Pedagogics, Associate Professor, Russian State Social University, 129226, Russia, Moscow, Wilhelm Pieck str., House 4, block 1, e-mail: fizzdorovie@gmail.com 